\title{
BALLESTER, JOSEP (ED.) (2015). Sobre l'horrible perill de la lectura. València: Universitat de València-Departament de Didàctica de la Llengua i la Literatura
}

Neste volume cuxo título homenaxea o coñecido texto voltairiano, o profesor Josep Ballester ofrécenos unha colección heteroxénea de textos á volta do libro e da actividade lectora (habería que apelidar esta lectura de "literaria"), que a miúdo adopta a forma dun eloxio da lectura, parafraseando agora a Érasmo. Ao mesmo tempo, esta heteroxeneidade articúlase coa presenza sostida dunha serie de tópicos que atravesan toda a obra (lectura como evasión, a soidade do lector, a relevancia da lectura na infancia). A colectánea, organizada en cinco capítulos que abordan diferentes dimensións do fenómeno, vai precedida dunha introdución do autor que aborda a lectura desde múltiplas perspectivas e péchase cunha extensa selección bibliográfica sobre o asunto.

$\mathrm{Na}$ Introdución o autor anticipa diferentes dimensións da lectura que estarán presentes nos textos da escolma. Comeza por, en alusión ao título do libro, remarcar o papel da lectura como antídoto para a ignorancia e, despois de achegar algúns datos sociolóxicos sobre a actividade lectora no estado español (incremento de lectores, lectura dixital moi incipiente), atende aos desafíos e alteracións na paisaxe da lectura por causa do libro dixital. Para Ballester "Parlem, clar és, de la inauguració de noves formes de llegir i, per tant, del sorgiment de nous perfils de lectors, caracteritzats per la hibridesa i per la fragmentació, trets característics de la tan esmentada postmodernitat dibuixada per Lyotard entre d'altres, però també, per la interactivitat i pel dinamisme inherent a les tecnologies emprades" (p. 20).

Fai una aproximación o autor, aínda na súa Introdución, a una definición de lectura (como proceso dialéctico, construción do sentido, proceso activo, creativo), tamén metafórica (lectura como loucura, como viaxe, como experiencia ou exploración histórica), sen esquecer o poder transformador da lectura e tampouco, é claro, algún episodios históricos que apuntan para o seu carácter "perigoso". Habería que destacar, asemade, o tratamento de Ballester da lectura e os nenos, onde outorga un papel de relevo aos pais como referentes lectores. Resaltando a relevancia desta actividade na construción do ser humano, apunta o autor en relación coa 
lectura na escola que "no pot ser vist sols com una tècnica d'aprenentatge sinó com una eina de civilització que ens obri les portes de tot un univers de conceptes, categories, idees i sentiments que han forjat la nostra tradició i que ens han de servir per a la realitat que ens envolta" (p. 34). Non está exenta de obstáculos a aproximación dos nenos da lectura, polo que reivindica "un aprenentatge per a la llibertat i per a l'autonomia de l'individu", apuntando que a "ràpida desalfabetització que sovint podem comprovar en els nostres adolescents ens deixa ben palés que han estat alfabetitzats incorrectament, que no han arribat a dominar els mecanismes de la lectura, que no han aconseguit abastar el nivell de lectura ràpida, silenciosa, interessada i crítica que podem considerar com a veritable lectura" (p. 35). Neste sentido remarca a importancia das estratexias adecuadas para o fomento dos hábitos lectores, lembrando aquí a Gianni Rodari e insistindo en que os plans de lectura non deben dirixirse só aos alumnos, mais deben envolver tamén a docentes e pais.

No primeiro dos capítulos ("Sobre el fet de llegir"), os diferentes textos convocados serven para compor unha paisaxe heteroxénea, ás veces, como non podía deixar de ser, reiterativa, pois xorden nas propostas de varios dos autores (a lectura como evasión, acceso a outros mundos,...): a aproximación desenfadada de Auden ao papel dos críticos literarios, xunto ao poder absorbente da lectura para o Proust neno, que define como "aquest miracle fecund d'una comunicació en el si de la solitud" (p. 60), ou o contributo de Joan Fuster, que reivindica os clásicos e reflexiona sobre a lectura como evasión e como coñecemento do mundo, ... Destacamos o texto de Antonio Mendoza, centrado na dimensión educativa da lectura, xa non só literaria, en que se pon de relevo a súa importancia na formación do individuo en termos de relacións sociais e actividade profesional (abordando sumariamente aspectos como a lectura como necesidade, como proceso de interacción, de construción de significado, como sedución), e chama a atención sobre a lectura como actividade fundamental para a "construcción de saberes". Enumera tamén o autor unha serie de supostos que deben presidir as nosas orientacións didácticas baseadas na interacción texto-lector, e resalta ao mesmo tempo que o lector debe ocupar un lugar central no proceso, pois dos seus coñecementos previos e habilidades lectoras depende a recepción do texto.

O segundo capítulo ("Sobre la història del llibre i de la lectura") inclúe un amplo excerto dun libro de Joan Fuster sobre o libro catalán, focando algún 
dos seus momentos máis relevantes: desde as súas orixes e os primeiros impresores, pasando polo período da decadencia da lectura e escrita en catalán na Idade Moderna (reducido o emprego da lingua á prosa utilitaria), ata o aparecemento da figura do editor no século XIX, chamando a atención sobre a relevancia do editor catalán para a impresión en castelán e a modesta recuperación da edición en catalán. Pola súa banda, Antonio Castillo Gómez, en "El despertar de los lectores", realiza unha abordaxe sociolóxica ao apoxeo do libro e a lectura no período ilustrado, coa incorporación ao público lector das mulleres, os nenos e a clase traballadora.

No terceiro bloque de excertos ("Sobre la figura del lector") o texto do poeta Pedro Salinas ("La soledad del lector"), coa súa distinción entre "leedor" e "lector", reivindica máis unha vez o entendemento da lectura como pracer, como actividade gratuíta sen finalidade instrumental, e reflexiona no seu delicioso texto sobre o espazo, o ruído, a soidade, a luz , a muller e a lectura. Pola súa banda, Jaume Cabré ("Tipus de lectors") refírese ao lector que aprecia, que é aquel que ten un "sentit tràgic de la lectura" (pola imposibilidade de ler todo o que lle interesa), o que se "somete" á lectura; ao crítico literario como lector privilexiado; ao lector maduro, non obrigado a completar lecturas aburridas, que vai deixando a ficción para pasar ás biografías, diarios e obras reflexivas; ou ao lector "fidel", respectuoso da obra do escritor. Este capítulo integra tamén un dos textos que, por varios motivos, conviría destacar da escolma de Ballester, da responsabilidade do Equipo Peonza ("Lectores infantiles y juveniles"). Alertan sobre a influencia negativa sobre a formación dos nenos da sobreexposición ás novas tecnoloxías. Vale a pena reproducir o seguinte fragmento, que espella o pensamento dos autores: "Walter Benjamin decía hace más de medio siglo que se vivía en un mundo con abundancia de estímulos y pobreza de experiencias. El tiempo que nos separa desde entonces no ha hecho otra cosa que corroborar su aserto y agudizar esa divergencia. Pero además esta inagotable corriente de estímulos impide su discriminación y sobre todo su jerarquización, resultando de todo ello que es la propia realidad la que es 'leída' de forma defectuosa" (p. 176). A lectura vén enriquecer o campo das experiencias. Apuntan tamén que as lecturas, como actualizacións dos textos, diverxen de xeración para xeración. No caso da xente nova de hoxe en día, do ensino secundario, verifícanse una serie de problemas na súa actividade lectora: dificultades en manter a atención, problemas co aproveitamento léxico do texto, non 
distanciamento (crítico) relativamente ao autor, descoñecemento de diferentes tipos de lecturas segundo o tipo de texto, interese en narracións de ritmo elevado, dificultades na mecánica da lectura. Os autores conclúen que "el nivel óptimo de calidad lectora al que aspiramos implica la confluencia de una percepción, una comprensión, una aceptación crítica, una clasificación jerárquica, una retención y una interrogación del texto. Todo ello exige atención, reflexión y elaboración; sin descuidar la importancia que la propia actitud y motivación del lector pueden tener en la comprensión" (p. 184).

Outro dos fragmentos que na nosa opinión debe ser resaltado é o que abre o espazo consagrado ao libro e a biblioteca ("Sobre el llibre i la biblioteca"), de título "Biblioteca escolar i lectura". Un estudo dos autores do texto pon de manifesto as causas polas que as bibliotecas escolares en España non teñen impacto sobre os hábitos lectores dos mozos, e os autores apuntan algunhas recomendacións neste sentido, como o feito de que docentes e bibliotecarios favorezan o primeiro acceso á lectura mediante a recomendación de lecturas adecuadas ou a programación de actividades que fomenten o gusto pola lectura. Para isto é necesario que a biblioteca teña uns fondos actualizados e variados, o que está lonxe de acontecer segundo os datos achegados polos autores. Detectan, ademáis, entre outros aspectos, que as actividades de promoción lectora están máis dirixidas a (e frecuentadas polos alunos de) educación primaria que a secundaria e centradas na lectura de ficción. Neste sentido, apuntan que, por unha banda, se debe estudar o que se está a facer na biblioteca pública (éxito dos clubes de lectura) e pensar en actividades máis adaptadas á xente nova, e por outra, destácase a necesidade da implicación de todos os actores da escola nestes labores. O capítulo péchase cunha proximación moi persoal de Mercé Escardó (Bibliote... què?) do que entende que é e o que debe ser unha biblioteca, lembrando que é un espazo dedicado fundamentalmente á lectura, e cunha abordaxe en clave de humor, a miúdo irónica, de Víctor Moreno (Los libros, esos objetos inertes), da importancia do libro nas nosas vidas.

O derradeiro bloque de textos ("Sobre estratègies del desig per llegir"), para alén de incluir unha versión en catalán do ben coñecido "Perché leggere i classici" de Italo Calvino, incorpora un texto de Roser Ros ("Tal fan els grans, tal fan els infants") que valoriza, tal como se desprende do título, a importancia dos adultos no proceso de aprendizaxe e desenvolvemento da capacidade e gusto lector nos nenos, da relevancia de ver ler que impulsa o desexo 
mimético da lectura, da iniciación e a competencia na lectura. En fin, o texto de Emili Teixidor ("Estratègies del desig o trucs per llegir") pecha o volume enumerando unha serie de estratexias favorecedoras da lectura: a preocupación polas propias lecturas que poderá ter efectos positivos sobre os outros, é dicir, a sedución pola imitación en lugar da imposición de ler; recomendar os libros adecuados ao perfil do lector; crear espazos, momentos para a lectura no ensino; practicar a mecánica da lectura, tamén en voz alta; estimular o interese perante os libros (mediante a ocultación ou proibición finxida); a lectura como aventura no descoñecido; trucos de profesores para grupos (dramatizacións e presentacións de libros, mudar o final dun libro, os clubes de lectura nas biblioteca, suliñar partes, escribir unha parodia do libro, facer unha versión en cómic ou cinematográfica) e exercicios individuais (ler unha liña cada día, pedir opinións a lectores fiables para seleccionar a lectura, facer listas de libros); a indiferencia, unha vez máis finxida.

Entréganos, en fin, o profesor Ballester una volume caleidoscópico que nos permite una aproximación múltipla ao fenómeno da lectura e tamén á súa problemática actual. Atendendo ás diferentes vertentes do fenómeno, con incidencia fundamentalmente na obra literaria, ofrece un traballo interesante, útil e ameno para todos os interesados no asunto, e que nos proporciona ao mesmo tempo numerosos argumentos e ferramentas para a abordaxe da lectura no contexto da escola e da sala de aula.

Pedro Dono López

Instituto de Letras e Ciências Humanas

Universidade do Minho 